\title{
Near-Infrared Fluorescent Probe for Imaging and Evaluating the Role of Vanin-1 in Chemotherapy
}

\author{
Pengpeng Lu, Caiyun Zhang, Lili Fu, Yinghui Wei, Yan Huang,* Xiaoyan Wang,* Changjun Lv, \\ and Lingxin Chen*
}

Cite This: Anal. Chem. 2021, 93, 10378-10387

Read Online

ACCESS | Llll Metrics \& More | 回 Article Recommendations | S1 Supporting Information

ABSTRACT: Pantetheinase (also known as Vanin-1) is highly expressed in the liver, kidneys, and intestine and is closely associated with a number of diseases. Vanin-1 can hydrolyze pantetheine to pantothenic acid (vitamin B5) and cysteamine and participate in the synthesis of glutathione (GSH). GSH is highly expressed in tumor cells and plays a major role in the resistance of tumor cells to cisplatin. Therefore, we urgently need a method to monitor the activity level of Vanin-1 in tumor cells and tissues and elucidate the relationship between the role of Vanin-1 in GSH synthesis and tumor resistance. Herein, we report a Cy-Pa fluorescent probe for imaging Vanin-1 in cells and in vivo that can qualitatively and quantitatively detect the fluctuation of Vanin-1 concentrations in HepG2 and HepG2/DDP cells or tumor tissues of tumorbearing mice. This probe shows excellent potential in in situ real-time monitoring of endogenous Vanin-1. Moreover, we proved that Vanin-1 can

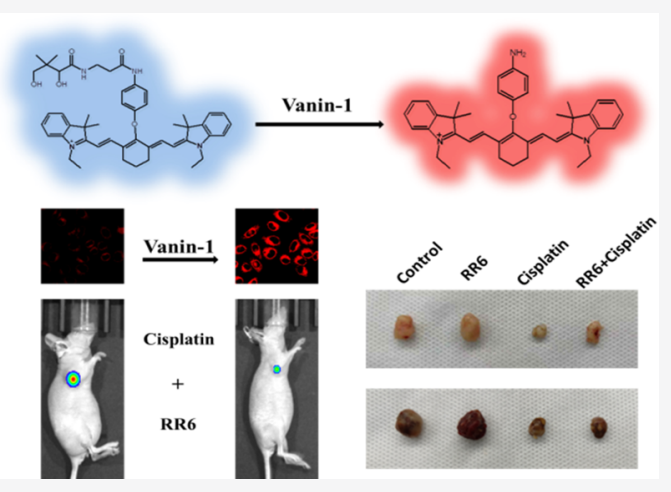
inhibit GSH synthesis using the probe. When the Vanin-1 inhibitor RR6 was used in combination with cisplatin, HepG2 and HepG2/DDP cells showed increased resistance to cisplatin, while the therapeutic efficiency of cisplatin was reduced in HepG2 and HepG2/DDP xenografts. In this study, Vanin-1 was shown to play an important role in the treatment of cancer, and the study of Vanin-1 may provide an idea for the treatment of cancer in the future.

$\mathrm{V}$ ascular noninflammatory molecule-1 (Vanin-1/VNN1) is a membrane-anchored pantetheinase that is anchored to the surface of epithelial cells by the glycosylphosphatidylinositol portion and was first identified as a new surface molecule in 1996. This molecule is highly expressed in the liver, kidneys, and intestine and has received much attention. ${ }^{2}$ Currently, owing to its pantetheinase activity, Vanin-1 is believed to be a major regulator of stress resistance in a variety of diseases. ${ }^{3,4}$ In many diseases, such as influenza, ${ }^{5}$ inflammation, ${ }^{6,7}$ diabetes mellitus, ${ }^{8-10}$ acute kidney injury, ${ }^{11,12}$ and soft tissue invasion of tumors, Vanin-1 activity has been detected. ${ }^{13}$ Pantothenic acid (PA) is a structural component of CoA, suggesting that Vanin-1 may be involved in coenzyme A metabolism, energy production, and lipid metabolism. ${ }^{14,15}$ However, cysteamine suppresses the regulation of endogenous glutathione (GSH) pools mediated by $\gamma$-glutamylcysteine synthetase $(\gamma$-GCS), the rate-limiting enzyme for GSH synthesis, ${ }^{16}$ thus leading to increased stores of GSH. ${ }^{8}$ As the most abundant endogenous antioxidant in organisms, GSH is a key mediator in many cellular events and protects cells from damage caused by oxidative stress. ${ }^{17}$ In addition, GSH is involved in many cellular metabolic activities, such as maintenance of redox homeostasis, mediation of signal transduction, and regulation of DNA synthesis. ${ }^{18,19}$ Most importantly, GSH also protects tumor cells from high levels of reactive oxygen species. ${ }^{20}$ Elevated levels of GSH have been observed in various types of tumors, and GSH plays an important role in the development of tumor resistance to the chemotherapeutic drug cisplatin, which significantly reduces the efficacy of cisplatin and leads to a decrease in the cure rate of tumors. $^{21,22}$

Since Vanin-1 can indirectly affect the synthesis of GSH, this paper mainly discusses the relationship between Vanin-1 and cisplatin resistance and seeks solutions to cisplatin resistance. Cisplatin is one of the most effective anticancer drugs among the many chemotherapy drugs widely used in cancer treatment. ${ }^{23}$ This drug functions by interfering with the DNA repair mechanism to cause DNA damage and induce apoptosis. In addition to DNA damage, oxidative stress is also one of the most important mechanisms of cisplatin toxicity. $^{24,25}$ However, the emergence of drug resistance seriously reduces the efficacy of cisplatin, and the development of drug resistance is one of the main reasons for the failure of chemotherapy in human malignant tumors. Recent studies

Received: June 6, 2021

Accepted: July 7, 2021

Published: July 19, 2021 
Scheme 1. (a) Synthesis Route to Cy-PA and (b) Reaction Mechanism of Cy-PA with Vanin-1
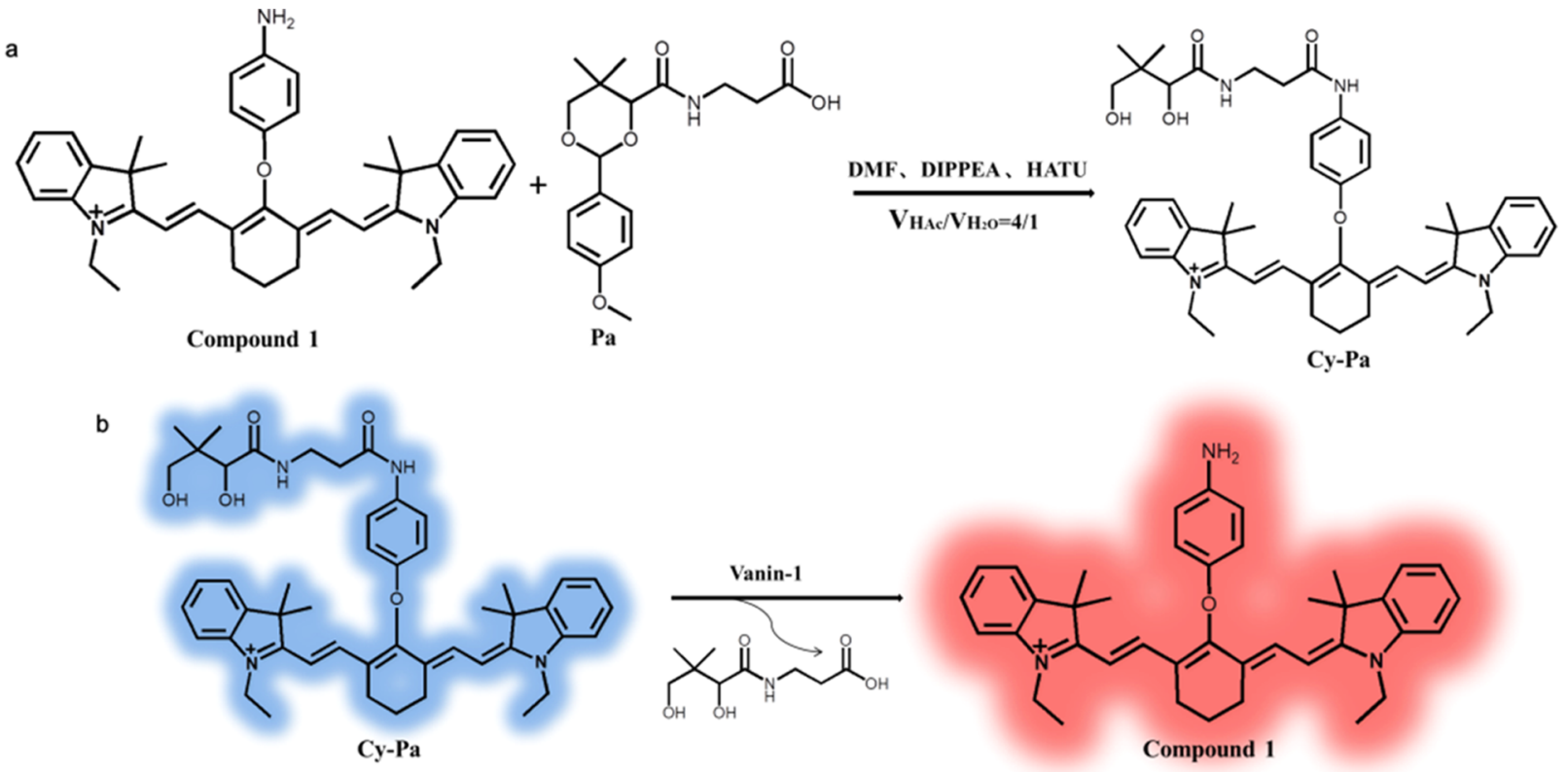

have shown that tumor resistance is mediated by different mechanisms that act at different stages of drug cytotoxicity, ranging from reducing drug accumulation in cells to eliminating chemically induced apoptosis. ${ }^{26-29}$ Among these mechanisms, GSH plays an important role in tumor therapy and the development of drug resistance, in addition to protecting tumor cells from high levels of ROS. Cisplatin resistance can be caused by the long-term administration of the GS-X pump on the cell membrane. ${ }^{30}$ Cisplatin exudation is dependent on the formation of the GSH-Pt complex. This process reduces the intracellular accumulation of cisplatin and reduces its efficacy. Vanin-1 is a GSH pool modulator that regulates $\gamma$-GCS activity. GSH synthesis may also play a role in regulating drug resistance. ${ }^{31}$ Therefore, this study aims to prove the role of inhibition of Vanin-1 activity in the treatment of tumors. To the best of our knowledge, few studies have been conducted on Vanin-1 due to the lack of strategies for in situ detection of the enzyme in living cells and in vivo. Therefore, there is an urgent need to develop efficient methods to analyze Vanin-1 in biological systems. Previous methods for the determination of the activity of Vanin-1 were usually indirect analysis by radioisotope labeling and spectrophotometry of cysteamine, leading to rough estimates and inaccurate results. $^{32-38}$ In 2010, Ruan et al. first reported the direct determination of Vanin-1 using fluorescence detection. ${ }^{39}$ However, it displayed a rather short excitation wavelength of $340 \mathrm{~nm}$ and is thus unfavorable for cell imaging. Lin et al. developed a bioluminescent probe for the detection of Vanin-1 in cells and mice, ${ }^{40}$ but this method requires specific instruments, which adds to the complexity of the experiment. Recently, $\mathrm{Hu}$ et al. reported a ratio fluorescent probe for the detection of Vanin-1. ${ }^{41}$ However, the probe has not been successfully used to detect Vanin-1 in vivo. Furthermore, Qian et al. reported a ratio fluorescent probe, but its maximum emission wavelength is only $645 \mathrm{~nm}$.

Herein, the near-infrared fluorescent probe $\mathrm{Cy}-\mathrm{Pa}$ was designed to test the level of Vanin-1 in living cells and in vivo (emission peak: $780 \mathrm{~nm}$, excitation $730 \mathrm{~nm}$ ). The Cy-Pa probe has a specific Vanin-1 substrate and is highly sensitive to
Vanin-1 in biological systems. In this study, the levels of Vanin1 in HepG2 and cisplatin-resistant HepG2 cell (HepG2/DDP) lines and corresponding tumor-bearing mouse models were successfully detected using Cy-Pa. Our results indicated that $\mathrm{Cy}-\mathrm{Pa}$ is an effective small-molecule fluorescent probe for the detection of Vanin-1. RR6 ((R)-2,4-dihydroxy-3,3-dimethyl- $N$ (3-oxo-4-phenylbutyl)butanamide) is a specific inhibitor of Vanin-1. We further confirmed that inhibition of Vanin-1 by RR6 could effectively increase the concentration of intracellular total GSH, and the synergistic effect of RR6 and cisplatin reduced the efficacy of cisplatin, which negatively affected the treatment of tumors. We believe that inhibition of Vanin-1 activity may be one of the reasons for the development of drug resistance in tumors. Therefore, the Cy-Pa probe may be a valuable tool for the exploration of drug resistance in tumors.

\section{EXPERIMENTAL SECTION}

Synthesis of Cy-Pa. Pantothenic acid (PA) (337 mg, 1.00 $\mathrm{mM}), \quad \mathrm{N}, \mathrm{N}$-diisopropylethylamine (DIPEA) (400 $\mu \mathrm{L}, 2.4$ $\mathrm{mM})$, and 2-(7-azabenzotriazol-1-yl)-N,N,N', $N^{\prime}$-tetramethyluronium hexafluorophosphate (HATU) $(380 \mathrm{mg}, 1.00 \mathrm{mM})$ were added to DMF $(5 \mathrm{~mL})$, and then stirred at $0{ }^{\circ} \mathrm{C}$ for 50 min. Compound 1 (502.2 $\mathrm{mg}, 0.86 \mathrm{mM})$ dissolved in DMF $(10 \mathrm{~mL})$ was added slowly to the above mixture, stirred at 25 ${ }^{\circ} \mathrm{C}$ for $12 \mathrm{~h}$ and then evaporated to remove the solvent. The above solid mixture was dissolved in an appropriate amount of $80 \%$ acetic acid $(\mathrm{AcOH} /$ water $=4: 1)$ and stirred for $3 \mathrm{~h}$. The solvent was removed under reduced pressure, and the crude product was purified using silica gel chromatography with $\mathrm{CH}_{2} \mathrm{Cl}_{2} / \mathrm{CH}_{3} \mathrm{OH}(9: 1, \mathrm{v} / \mathrm{v})$ as the eluent $(520.5 \mathrm{mg}, 57 \%) .{ }^{1} \mathrm{H}$ NMR (500 MHz, $\left.\mathrm{CDCl}_{3}-d_{1}\right) \delta(\mathrm{ppm}): 10.59(\mathrm{~s}, 1 \mathrm{H}), 8.00-$ $7.97(\mathrm{~m}, 2 \mathrm{H}), 7.87-7.85(\mathrm{~m}, 2 \mathrm{H}), 7.35-7.31(\mathrm{~m}, 4 \mathrm{H}), 7.23-$ $7.21(\mathrm{~m}, 6 \mathrm{H}), 7.05-7.03(\mathrm{~m}, 2 \mathrm{H}), 6.96-6.94(\mathrm{~m}, 2 \mathrm{H}), 5.92-$ $5.89(\mathrm{~m}, 2 \mathrm{H}), 4.33-4.31(\mathrm{~m}, 1 \mathrm{H}), 4.01-3.99(\mathrm{~m}, 5 \mathrm{H}), 3.38(\mathrm{~s}$, $2 \mathrm{H}), 2.68-2.66(\mathrm{~m}, 6 \mathrm{H}), 2.04(\mathrm{~s}, 6 \mathrm{H}), 1.42-1.39(\mathrm{~m}, 14 \mathrm{H})$, $0.97-0.82(\mathrm{~m}, 6 \mathrm{H}) .{ }^{13} \mathrm{C} \mathrm{NMR}\left(125 \mathrm{MHz}, \mathrm{CDCl}_{3}-d_{1}\right) \delta(\mathrm{ppm})$ : $174.29,171.98,170.86,165.49,155.81,142.90,141.45,141.15$, $134.61,130.94,128.84,128.60,125.34,122.62,122.29,121.81$, 

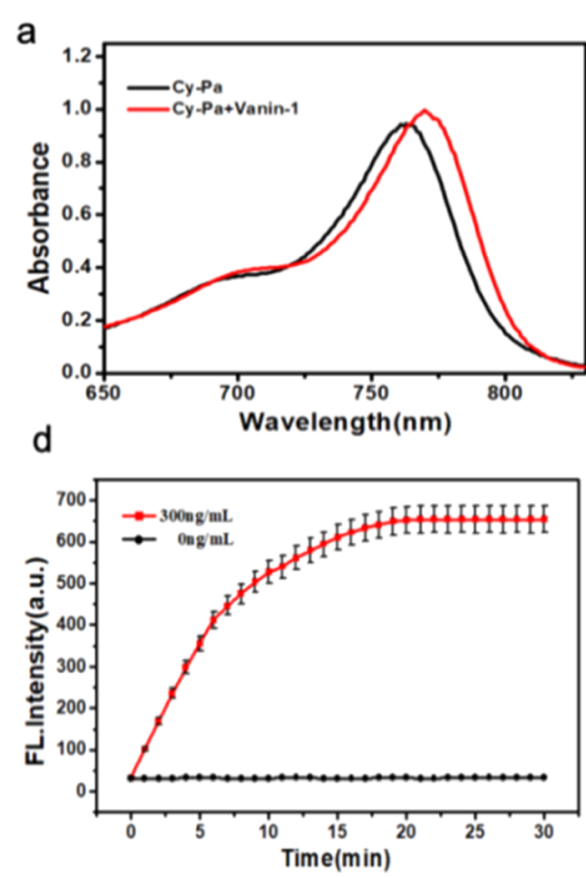

b

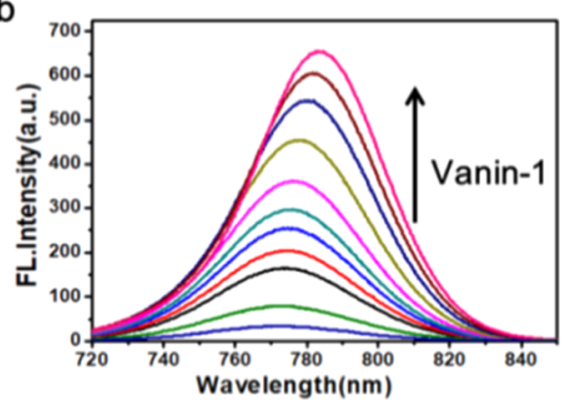

e

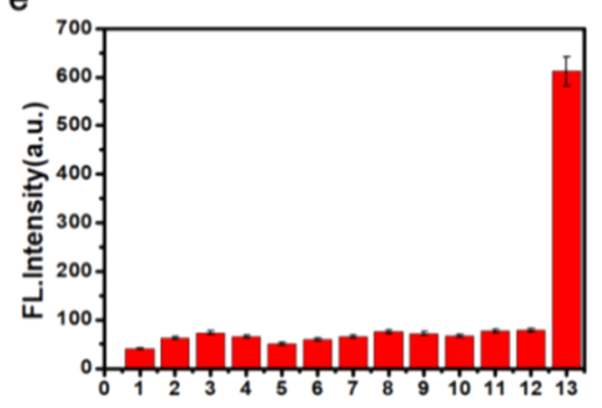

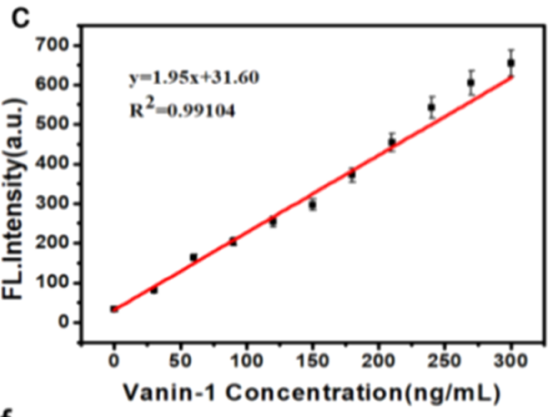

$f$

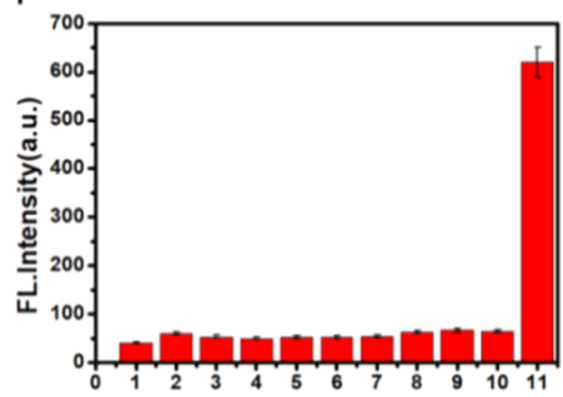

Figure 1. Spectral properties of Cy-Pa. (a) Absorption spectra of Cy-Pa and Cy-Pa + Vanin-1. The black curve is the absorption spectrum of Cy-Pa. The red curve is observed after treatment with $300 \mathrm{ng} / \mathrm{mL}$ Vanin-1. (b) Changes in the fluorescence emission spectra of Cy-Pa (10 $\mu \mathrm{M})$ with various concentrations of Vanin-1 $(0,30,60,90,120,150,180,210,240,370$, and $300 \mathrm{ng} / \mathrm{mL})$. (c) The plot of the linear relationship between the relative fluorescence intensity at $680 \mathrm{~nm}$ and concentrations of Vanin-1 $(0-300 \mathrm{ng} / \mathrm{mL})$. (d) Plot of fluorescence intensity of Cy-Pa $(10 \mu \mathrm{M})$ against the reaction time in the presence of varied concentrations of Vanin-1 $(0$ and $300 \mathrm{ng} / \mathrm{mL})$. (e) Fluorescence responses of Cy-Pa $(10 \mu \mathrm{M})$ to treatments with a series of biomolecules $(1 \mathrm{mM})$, GGT $(50 \mathrm{U} / \mathrm{L})$, tyrosinase $(\mathrm{Tyr})(100 \mathrm{ng} / \mathrm{mL})$, and Vanin- $1(300 \mathrm{ng} / \mathrm{mL})$ for $30 \mathrm{~min}$ at $37^{\circ} \mathrm{C}$ : (1) Blank, (2) GSH, (3) D-cysteine, (4) glucose, (5) VcNa, (6) L-valine, (7) Hcy, (8) GGT, (9) TYR, (10) serine (Ser), (11) lysine (Lys), (12) arginine (Arg), and (13) Vanin-1. (f) Bioluminescence imaging of Cy-Pa toward various inorganic salts (100 $\mu \mathrm{M})$ and Vanin-1 (300 ng/mL): (1) Blank, (2) $\mathrm{PbCl}_{2}, 3 . \mathrm{MgCl}_{2}, 4 . \mathrm{BaCl}_{2}$, (5) $\mathrm{MnSO}_{4},(6) \mathrm{CaCl}_{2}$, (7) $\mathrm{ZnCl}_{2},(8) \mathrm{AlCl}_{3},(9) \mathrm{CuSO}_{4},(10) \mathrm{FeCl}_{3}$, and (11) Vanin-1. $\lambda_{\mathrm{ex}}=730 \mathrm{~nm}, \lambda_{\mathrm{em}}=$ $780 \mathrm{~nm}$. The measurements were performed in $10 \mathrm{mM}$ HEPES $(\mathrm{pH} 7.4)$ at $37^{\circ} \mathrm{C}$.

$114.25,109.93,98.75,70.53,65.59,49.28,39.19,37.58,36.18$ $30.57,29.33,27.85,24.26,22.13,22.09,21.11,20.45,19.19$, 13.74, 12.16. LC-MS (ESI): $m / z$ calcd for $\mathrm{C}_{49} \mathrm{H}_{61} \mathrm{~N}_{4} \mathrm{O}_{5}{ }^{+}[\mathrm{M}]^{+}$ 785.46, found 785.62.

Cell Transfection. HepG2 and HepG2/DDP cells were placed in a six-well plate. After the confluence rate was approximately $70 \%, 2 \mu \mathrm{g}$ of plasmid DNA (human Vanin-1 gene, cDNA clone expressing plasmid with the OFPSpark tag) and $2.5 \mu \mathrm{L}$ of lipofectamine 2000 were added to the serum-free medium according to the instructions. After $6 \mathrm{~h}$ of culture, the culture medium was replaced with a complete medium for another $24 \mathrm{~h}$. The transfection efficiency was confirmed by Western blotting.

Cell Imaging. Fluorescent images were acquired on an Olympus FV1000 confocal laser scanning microscope with an objective lens $(\times 40)$. Cells were plated on Petri dishes $(\Phi=20$ $\mathrm{mm}$ ) and allowed to adhere for $24 \mathrm{~h}$ before imaging. The probe was added to the culture plates, which were filled with 1 $\mathrm{mL}$ of fresh complete medium. All of the experimental cells were incubated with $\mathrm{Cy}-\mathrm{Pa}$ at $37{ }^{\circ} \mathrm{C}$ for $30 \mathrm{~min}$, and imaging was performed by laser scanning confocal microscopy. Fluorescence changes were quantified by flow cytometry.

\section{RESULTS AND DISCUSSION}

Design Strategies for the $\mathrm{Cy}-\mathrm{Pa}$ Probes. The synthetic approaches for the Cy-Pa probe are outlined in Scheme S1. All synthetic compounds were characterized using ${ }^{1} \mathrm{H} \mathrm{NMR},{ }^{13} \mathrm{C}$ NMR, and high-resolution mass spectrometry (HRMS). The synthetic details of compounds are shown in the Supporting
Information. As shown in Scheme 1, in this work, we combined 4-aminophenol with fluorophore $\mathrm{Cy}-7$ to obtain compound 1 due to its high molar absorption coefficient and near-infrared (NIR) emission. Near-infrared fluorescent dye compound 1 was selected as the fluorophore (emission peak: $780 \mathrm{~nm}$, excitation $730 \mathrm{~nm}$ ), and pantothenic acid was selected as the detection group. The integration of $\mathrm{Pa}$ into the fluorescence platform dramatically quenched the fluorescence of compound 1. We speculated that the fluorescence properties of compound 1 can be modulated by a photoinduced electron transfer (PET) from the excited fluorophore to a strongly electron-withdrawing group (donor-excited PET, d-PET). ${ }^{42,43}$ The probe $\mathrm{Cy}-\mathrm{Pa}$ was prepared by a simple condensation reaction between compound 1 and pantothenic acid. Once the probe $\mathrm{Cy}-\mathrm{Pa}$ encounters Vanin-1, Vanin-1 could specifically recognize and cleave the peptide bond of the probe to release dye compound 1, which results in the emergence of a $780 \mathrm{~nm}$ emission peak. Therefore, the peptide bond as the Vanin-1 reaction unit exhibits a specific reaction and high sensitivity.

Spectroscopic Measurements. The absorption and fluorescence spectra of $\mathrm{Cy}-\mathrm{Pa}(10 \mu \mathrm{M})$ were measured under simulated physiological conditions (10 mM HEPES buffer, $\mathrm{pH}$ 7.4). The maximum absorption wavelength was $760 \mathrm{~nm}$ (Figure 1a). When Vanin-1 (300 ng/mL) was added to the solution of $10 \mu \mathrm{M}$ probes, a new absorption peak appeared at $780 \mathrm{~nm}$. In addition, the fluorescence of $\mathrm{Cy}-\mathrm{Pa}$ was measured with different doses of Vanin-1 $(0-300 \mathrm{ng} / \mathrm{mL})$ under the same conditions (Figure $1 \mathrm{~b}$ ). With the increase of Vanin-1 concentration, the associated fluorescence intensity increased 

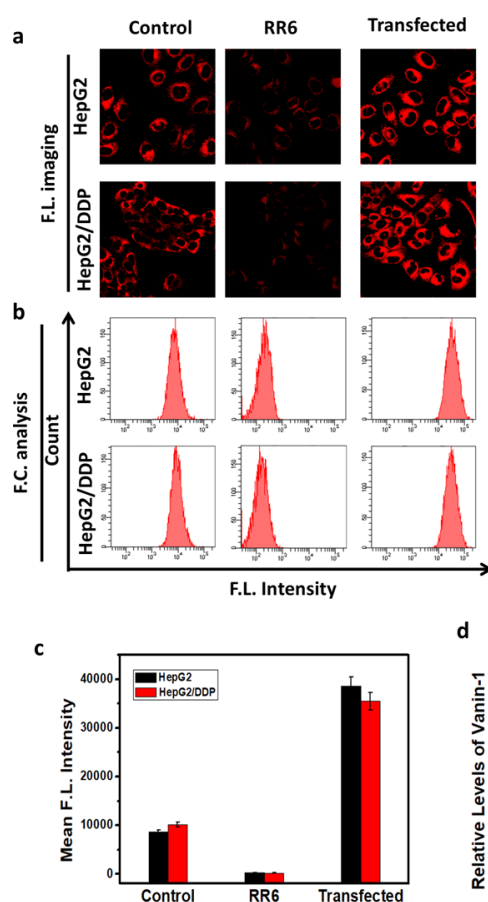

d
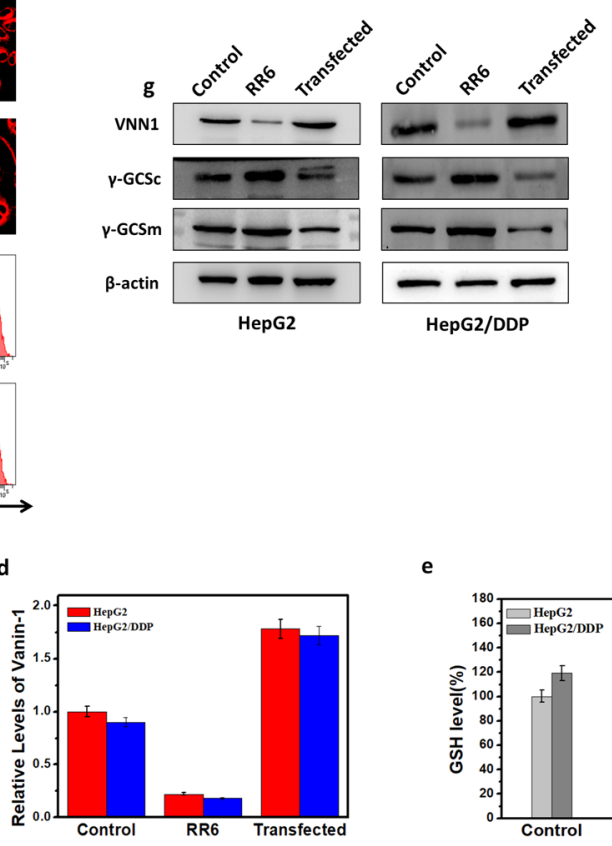

e
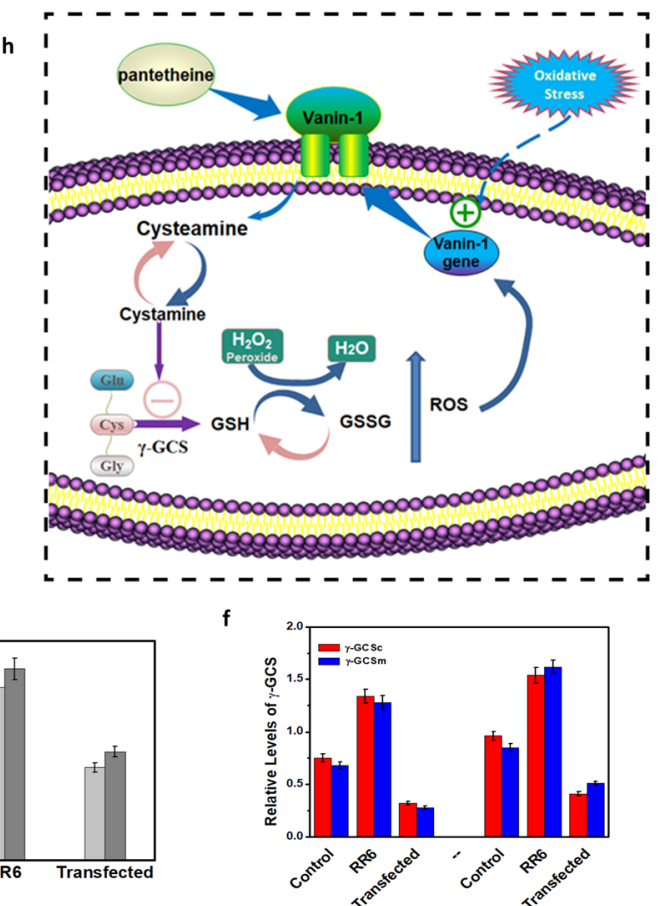

Figure 2. Confocal microscopy images and flow cytometry assay of HepG2 cells and HepG2/DDP cells for measuring Vanin-1 levels in living cells. The RR6 group was incubated with $100 \mu \mathrm{M} \mathrm{RR6} \mathrm{for} 30 \mathrm{~min}$, the transfected group was transfected with the human Vanin-1 gene, and the control group was not treated. (a) Confocal microscopy images of Vanin-1 level with Cy-Pa (10 $\mu \mathrm{M})$ in cells for 30 min (scale bars: $20 \mu \mathrm{m})$. (b) Flow cytometry analysis of (a). (c) Mean fluorescence intensity of HepG2 cells and HepG2/DDP cells in different groups in (a) and (b). (d) Quantitative analysis of Vanin-1 expression in (g). (e) The real GSH concentration of HepG2 cells and HepG2/DDP cells in control groups, RR6 groups, and transfected groups. (f) Quantitative analysis of $\gamma$-GCSc and $\gamma$-GCSm expression in (g). (g) Western Blot analysis of the changes of Vanin-1, $\gamma$-GCSc, and $\gamma$-GCSm levels of HepG2 cells and HepG2/DDP cells in the three groups, $\beta$-actin was utilized as the internal control. (h) As a sensor of oxidative stress, Vanin-1 is regulated during stress induction and releases cysteamine into tissues through the metabolism of pantothenic acid (vitamin B5). Cysteamine affects $\gamma$-GCS-mediated regulation of endogenous GSH pool, thereby influencing cellular responses to oxidative stress injury.

with the peak value centered at $780 \mathrm{~nm}$ because the peptide bond of $\mathrm{Cy}-\mathrm{Pa}$ was hydrolyzed to release a fluorophore. The excitation wavelength of the probe was $730 \mathrm{~nm}$. The linear concentration-dependent fluorescence response range between Cy-Pa and Vanin-1 was $0-300 \mathrm{ng} / \mathrm{mL}$ (Figure 1c). The equation obtained from the calibration curve is $F_{780 \mathrm{~nm}}=$ 1.95 [Vanin-1] $\mathrm{ng} / \mathrm{mL}+31.6\left(R^{2}=0.9910\right)$. The limit of detection for Vanin-1 was $0.85 \mathrm{ng} / \mathrm{mL}(3 \sigma / k$, where $\sigma$ was the standard deviation of blank measurement and $\mathrm{k}$ was the slope of the regression equation), indicating that the $\mathrm{Cy}$-Pa probe had a high sensitivity to Vanin-1 under simulated conditions. The above results demonstrate that our probe is an effective chemical tool for qualitative and quantitative detection of Vanin-1.

Kinetic Investigations of Cy-Pa toward Vanin-1. We assessed the response of $\mathrm{Cy}-\mathrm{Pa}$ to Vanin-1 under simulated physiological conditions (Figure 1d). The fluorescence curves of Cy-Pa at different concentrations of Vanin-1 ( 0 and $300 \mathrm{ng} /$ $\mathrm{mL}$ ) were studied for $30 \mathrm{~min}$. The fluorescence intensity did not change without Vanin-1 addition, but when the concentration of Vanin-1 was $300 \mathrm{ng} / \mathrm{mL}$, the fluorescence intensity became stronger as the reaction time increased, and the fluorescence signal reached a plateau within $20 \mathrm{~min}$. These results indicate that $\mathrm{Cy}-\mathrm{Pa}$ shows a very rapid response to Vanin-1. The rapid response behavior of the Cy-Pa probe enables the unique ability of real-time biological imaging of intracellular Vanin-1.
Selectivity of Cy-Pa toward Vanin-1. Good selectivity is an important index to evaluate the performance of probes, especially for biological imaging probes applied in complex biological systems. Therefore, the selectivity of $\mathrm{Cy}-\mathrm{Pa}$ to Vanin-1 was evaluated under simulated biological conditions $\left(\mathrm{pH} \mathrm{7.4,} 37^{\circ} \mathrm{C}\right)$. As illustrated in Figures 1e,f, the probe was incubated with glutathione (GSH), D-cysteine, glucose, $\mathrm{VcNa}$, L-valine, homocysteine (Hcy), $\gamma$-glutamyl transpeptidase (GGT), tyrosinase (Tyr), serine (Ser), lysine (Lys), arginine (Arg), and inorganic salts $\left(\mathrm{PbCl}_{2}, \mathrm{MgCl}_{2}, \mathrm{BaCl}_{2}, \mathrm{MnSO}_{4}\right.$, $\mathrm{CaCl}_{2}, \mathrm{ZnCl}_{2}, \mathrm{AlCl}_{3}, \mathrm{CuSO}_{4}, \mathrm{FeCl}_{3}$ ). The experimental results clearly showed that none of these substances can trigger the fluorescence signal, and the significant increase in fluorescence emission can occur only in the presence of Vanin-1. In conclusion, these results confirmed that $\mathrm{Cy}-\mathrm{Pa}$ is an ideal and effective tool for the sensitive detection of Vanin-1 levels in biological systems.

We also studied the spectral properties of Cy-Pa with Vanin1 at different $\mathrm{pH}$ values. As shown in Figure S2, the fluorescence of the probe does not change significantly in the $\mathrm{pH}$ range of $4-9$, indicating that $\mathrm{Cy}-\mathrm{Pa}$ has excellent stability over a wide $\mathrm{pH}$ range. To verify whether the $\mathrm{Cy}-\mathrm{Pa}$ reacts with RR6 or cisplatin. As shown in Figure S3, the RR6 group, cisplatin group, or RR6 + cisplatin group exhibit no significant increase in vitro, only upon addition of Vanin-1 a remarkable increase in fluorescence intensity could be observed. Therefore, RR6 and cisplatin have almost no effect on the Cy-Pa fluorescence. 

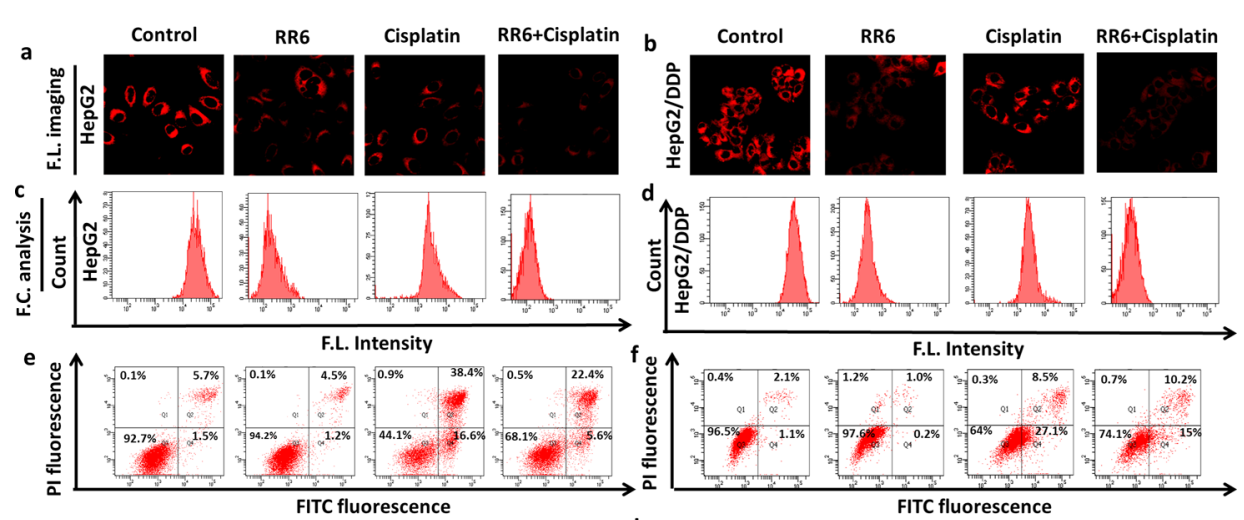

g
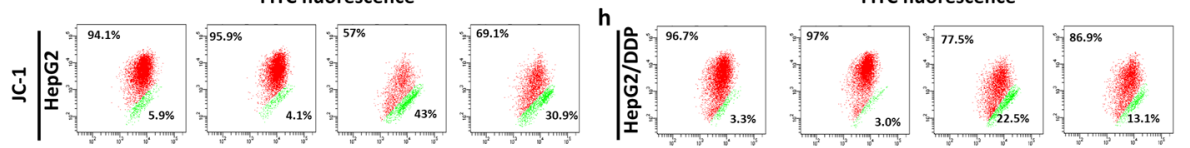

Cleaved-caspase 3
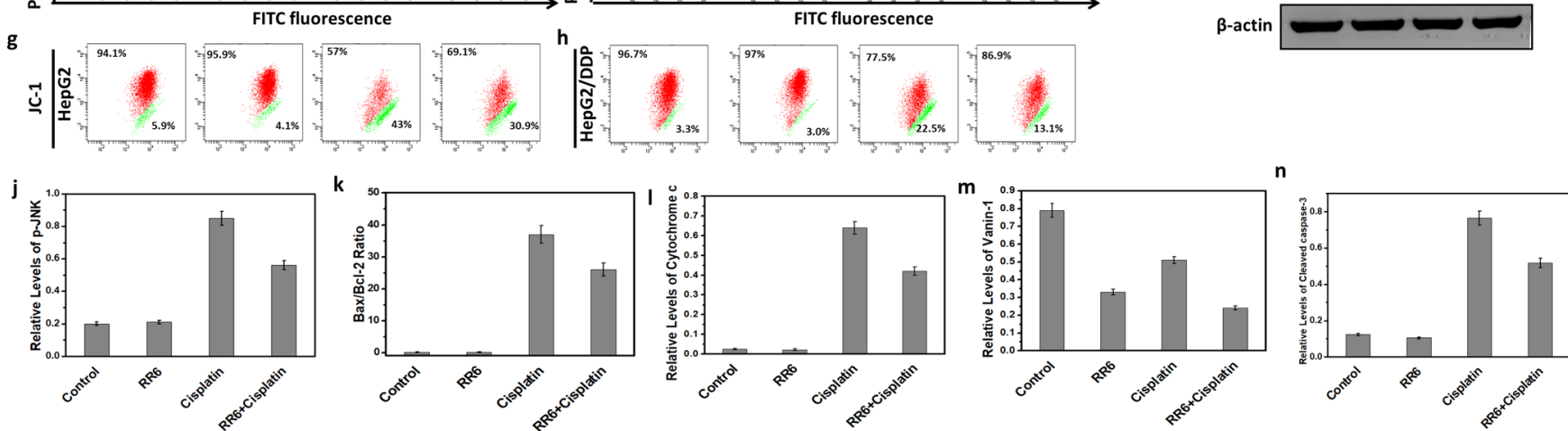

Figure 3. Mechanism of the anti-apoptotic effect of RR6 in HepG2 and HepG2/DDP cells. (a) and (b) Confocal microscopy images of Vanin-1 level with Cy-Pa $(10 \mu \mathrm{M})$ in HepG2 and HepG2/DDP cells for $30 \mathrm{~min}$. The cells in the first group were untreated. Those in the second group were treated with $100 \mathrm{mM}$ RR6 individually for $8 \mathrm{~h}$ before imaging. The cells in the third group were treated with $10 \mu \mathrm{g} / \mathrm{mL}$ cisplatin for $24 \mathrm{~h}$ before imaging. Those in the fourth group were co-treated with $100 \mathrm{mM} \mathrm{RR} 6$ for $8 \mathrm{~h}$ and $10 \mu \mathrm{g} / \mathrm{mL}$ cisplatin for $24 \mathrm{~h}$, respectively (scale bars: 20 $\mu \mathrm{m})$. (c) and (d) Flow cytometry analysis of (a) and (b). (e) and (f) Apoptosis analysis of two kinds of HepG2 cancer cells as introduced in (a) and (b). Viable cells (FITC $\left.{ }^{-} / \mathrm{PI}^{-}\right)$, early apoptosis $\left(\mathrm{FITC}^{+} / \mathrm{PI}^{-}\right)$, late apoptosis, and necrosis $\left(\mathrm{FITC}^{+} / \mathrm{PI}^{+}\right)$. (g) and (h) Mitochondrial membrane potential analyzed by JC-1. (i) Western blotting analysis of Vanin-1, p-JNK, cytochrome c, Bax, Bcl-2, and cleaved caspase 3. (j) Statistical analysis of p-JNK protein expression. (k) Statistical analysis of the Bax to Bcl-2 protein expression ratio. (l) Statistical analysis of cytochrome c protein expression. (m) Statistical analysis of Vanin-1 protein expression. (n) Statistical analysis of cleaved caspase 3 protein expression.

Imaging of Vanin-1 in Living Cells. The above experiments proved that the Cy-Pa probe had higher selectivity for Vanin-1, and we subsequently explored the application of the Cy-Pa probe in the detection of Vanin-1 in living cells. HepG2 cells and HepG2/DDP cells were used in this study. HepG2/DDP is a cell line with strong resistance to cisplatin. Before the experiment, CCK- 8 assays were used to detect the cytotoxicity of different concentrations $(0-100 \mu \mathrm{M})$ of the CyPa probe on HepG2 cells and HepG2/DDP cells. When the probe concentration was $100 \mu \mathrm{M}$, the survival rate of both types of cells remained above $83 \%$, and the results showed low cytotoxicity of the Cy-Pa probe to HepG2 and HepG2/DDP living cells (Figure S1). The $\mathrm{IC}_{50}$ value of HepG2/DDP cells was $8 \mu \mathrm{g} / \mathrm{mL}$.

Previous studies have shown that RR6 is currently the most effective Vanin-1 inhibitor; it is selective and displays excellent bioavailability and potency. ${ }^{44}$ To verify that our probe can effectively detect Vanin-1 in living cells, we pretreated HepG2 and HepG2/DDP cells with $100 \mu \mathrm{M}$ RR6 for $30 \mathrm{~min}$ to lower the Vanin-1 level before imaging. With the addition of RR6, the fluorescence intensity was significantly decreased compared with that of the control group, illustrating that the Vanin-1 level in cells decreased. Furthermore, transfected HepG2 and HepG2/DDP cells were immediately imaged, and we found that the cells transiently transfected with the human Vanin-1 gene showed stronger fluorescence intensity than the control cells (Figure 2a). The bright-field images of Figure 2a are shown in Figure S4. To further verify the fluorescence variation among the three groups of cells, the above experimental results were confirmed by flow cytometry (Figure $2 b$ ). The average fluorescence intensities of the three types of cells are displayed in Figure 2c. In addition, the changes in Vanin-1 levels in these three groups were confirmed by Western blot assays. The Western blot results were consistent with fluorescence images and flow cytometry analysis results (Figure $2 \mathrm{~g}, \mathrm{~d}$ ). The above data suggest that the probe $\mathrm{Cy}-\mathrm{Pa}$ is a simple and effective tool for the detection of Vanin-1 levels in cells.

$\gamma$-GCS is a rate-limiting enzyme for GSH synthesis, ${ }^{16}$ and its activity is inhibited by cystamine. ${ }^{45}$ As shown in Figure $2 \mathrm{~h}$, Vanin-1 has pantetheinase activity and is responsible for the production of cysteamine. ${ }^{46}$ Cysteamine can be oxidized to its disulfide, cystamine, and this reaction is reversible. $\gamma$-GCS is inhibited by high levels of cysteamine, which depletes the intracellular storage of GSH. Therefore, we next evaluated the expression levels of two subtypes of $\gamma$-GCS $(\gamma$-GCSc and $\gamma$ GCSm) in the above three groups of cells. The results are shown in Figure 2g,f. The expression levels of $\gamma$-GCSc and $\gamma$ GCSm in the RR6 group were higher than those in the control group, and in contrast, the transfection group showed lower expression levels than the control group. To determine the true concentration of GSH in the cells, we determined the content of GSH using a reduced GSH colorimetric assay kit (Figure 2e) according to the manufacturer's instructions, and the experimental results were consistent with the trend of the 
Western blot assays. The results showed that the addition of RR6 inhibited the activity of Vanin-1 and reduced the level of cysteamine. Low levels of cysteamine led to enhanced $\gamma$-GCS activity and, consequently, led to elevated endogenous GSH stores in cells.

Evaluation of Anti-Apoptotic Effects of Vanin-1 Inhibitors. As one of the most effective chemotherapy drugs for the treatment of solid tumors, cisplatin has been widely used to treat different types of tumors. ${ }^{23}$ In general, cisplatin is thought to function by damaging DNA and inducing oxidative stress to kill cancer cells. ${ }^{24}$ Unfortunately, high levels of GSH protect cells from oxidative stress, and long-term administration can lead to increased cisplatin outflow because the glutathione-X pump acts on the cell membrane, which reduces intracellular cisplatin levels and leads to reduced cisplatin efficacy, a major mechanism of drug resistance in tumors. ${ }^{30} \mathrm{We}$ demonstrated that the intracellular glutathione content is regulated by Vanin-1, which encouraged us to explore how changing the activity of Vanin-1 during chemotherapy may affect the therapeutic effect. As shown in Figure 3, HepG2 cells were divided into four groups. The first group was selected as the control. The cells in the second group were treated with $100 \mathrm{mM}$ RR6 for $8 \mathrm{~h}$ before imaging, and Vanin-1 activity was almost completely inhibited. The cells in the third group were treated with $10 \mu \mathrm{g} / \mathrm{mL}$ cisplatin for $24 \mathrm{~h}$ before imaging. The cells in the fourth group were co-treated with $100 \mathrm{mM}$ RR6 for $8 \mathrm{~h}$ and $10 \mu \mathrm{g} / \mathrm{mL}$ cisplatin for $24 \mathrm{~h}$. The cells in each group were incubated with $\mathrm{Cy}-\mathrm{Pa}$ at $37{ }^{\circ} \mathrm{C}$ and imaged by laser scanning confocal microscopy. As expected, the fluorescence intensity were as follows: control group > cisplatin group > RR6 group > RR6 + cisplatin group (Figure 3a). The brightfield images of Figure 3 are shown in Figure S5. These results revealed that the levels of Vanin-1 fluctuated, and the level of Vanin-1 decreased most significantly in the RR6 + cisplatin group. Upon the addition of cisplatin alone, the level of Vanin1 decreased slightly, which may be caused by the decrease in the number of living cells. We further used flow cytometry to detect the changes in fluorescence intensity, and the results were consistent with those of fluorescence imaging (Figure 3c). Western blot analysis confirmed the fluctuation of Vanin-1 levels in the four groups (Figure $3 \mathrm{i}, \mathrm{m}$ ). The variation trend was consistent with the previous experimental results.

In addition to DNA damage, oxidative stress is one of the most important mechanisms of cisplatin toxicity. Mitochondria are the major targets of cisplatin-induced oxidative stress, which results in the loss of mitochondrial protein sulfhydryl groups, inhibition of calcium uptake, and reduction of mitochondrial membrane potential. ${ }^{25}$ Next, several apoptotic markers were used to study the apoptosis of cells in the above four groups. When mitochondria are damaged, $\mathrm{Ca}^{2+}$ is released into the cytoplasm, leading to changes in the mitochondrial membrane potential $\left(\Delta \Psi_{\mathrm{m}}\right)$, which is a biomarker of early apoptosis. In the following work, we measured changes in $\Delta \Psi_{\mathrm{m}}$ using the red/green fluorescence ratio (Figure $3 \mathrm{~g}$ ). The control groups and the RR6 groups had high red/green fluorescence intensity ratios, while the red/green fluorescence intensity ratios of the cisplatin groups and the cisplatin + RR6 groups decreased to varying degrees, and the degree of decrease was greater in the cisplatin groups. This finding indicates that mitochondrial damage was the most serious in the cisplatin group. RR6 alone did not exhibit any effect on mitochondrial damage, but when it was combined with cisplatin, the damaging effect of cisplatin on mitochondria was reduced.
Thus, RR6 exhibited a cell-protective effect that reduced the efficacy of cisplatin. The apoptosis of cells was also analyzed using the Annexin V-FITC/PI Apoptosis Detection Kit (Figure 3e). Both the control group and the RR6 group maintained high levels of survival with little difference, which indicated that RR6 alone does not increase the rate of apoptosis. Then, we found that the percentage of early and late apoptotic cells increased in both the cisplatin groups and the cisplatin + RR6 groups, but the cisplatin groups showed more severe apoptosis than the combined groups. This finding is consistent with the results of the JC-1 assay. Furthermore, we performed JC-1 and Annexin V-FITC/PI apoptosis experiments on HepG2/DDP cells under the same conditions and obtained the same results (Figure $3 \mathrm{~b}, \mathrm{~d}, \mathrm{f}, \mathrm{h}$ ). These results indicate that inhibition of Vanin-1 can reduce the killing effect of cisplatin on HepG2 cells and HepG2/DDP cells. Therefore, we hypothesized that the inhibition of Vanin-1 activity might be one of the reasons for the development of cisplatin resistance in tumor cells.

The pharmacological effects of cisplatin could lead to DNA and mitochondrial damage, which leads to changes in apoptosis-related factors. According to previous reports, pJNK expression first occurs in mitochondrial apoptosis, and then, the proportion of $\mathrm{Bax}$ and $\mathrm{Bcl}-2$ is increased. Cytochrome $\mathrm{c}$ is the downstream effector of Bax and Bcl-2. Cytochrome $\mathrm{c}$ is located on the outer membrane of mitochondria. ${ }^{47}$ When the mitochondrial membrane potential collapses, cytochrome $\mathrm{c}$ is released from the mitochondria into the cytoplasm and activates the apoptotic executor cleaved caspase $3 .^{48,49} \mathrm{We}$ further determined the levels of these apoptosis-related factors in the four groups of HepG2/DDP cells. The expression of $\mathrm{p}$ JNK, Bax, Bcl-2, cytochrome C, and cleaved caspase 3 was examined using Western blot analysis. Compared with the control group, the expression level of p-JNK was not different in the RR6 group, and the expression of p-JNK was upregulated after cisplatin administration. However, when RR6 was combined with cisplatin, the upregulation of p-JNK expression was weakened (Figure 3i,j). Similarly, when RR6 was combined with cisplatin, the ratio of Bax to $\mathrm{Bcl}-2$ was lower than that in the cisplatin group (Figure 3i,k). As expected, the addition of RR6 reduced the cisplatin-mediated upregulation of JNK expression and the ratio of Bax to Bcl-2. At this point, the mitochondrial membrane potential collapsed, and cytochrome $\mathrm{c}$ was released from the mitochondria. The levels of cytochrome $c$ and cleaved caspase 3 were evaluated in the cytoplasm, which increased in the cisplatin group (Figure $3 \mathrm{i}, 1, \mathrm{n})$. The addition of RR6 resulted in a decrease in cytochrome $\mathrm{c}$ and cleaved caspase 3 levels in the cytoplasm. This finding was consistent with the results of analysis performed using JC-1 kit and Annexin V-FITC/PI assay for apoptosis. Herein, we emphasized that administration of the Vanin-1 inhibitor RR6 results in an increase in intracellular GSH. For HepG2 and drug-resistant HepG2/DDP cells, when cisplatin was combined with RR6, the efficacy of cisplatin was reduced, and the resistance of tumor cells to cisplatin was increased, which weakened tumor treatment.

Imaging of Vanin-1 in Tumor-Bearing Mice. Encouraged by the fact that the inhibition of Vanin-1 activity can reduce cisplatin-induced apoptosis in cancer cells, we next investigated whether the same treatment results can be produced in vivo in mice. During cancer treatment, drug resistance of cancer cells is a challenging problem that urgently needs to be solved. HepG2 and HepG2/DDP xenograft 


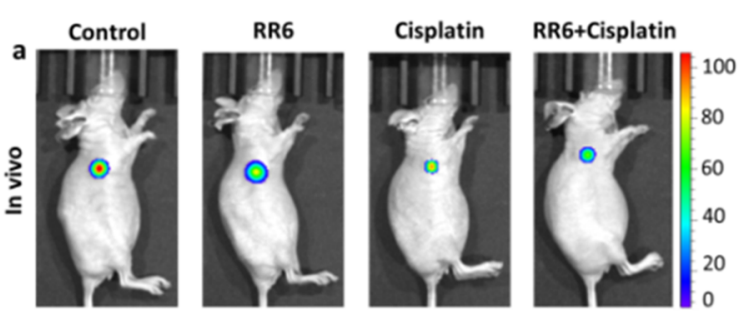

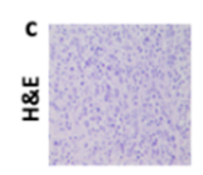
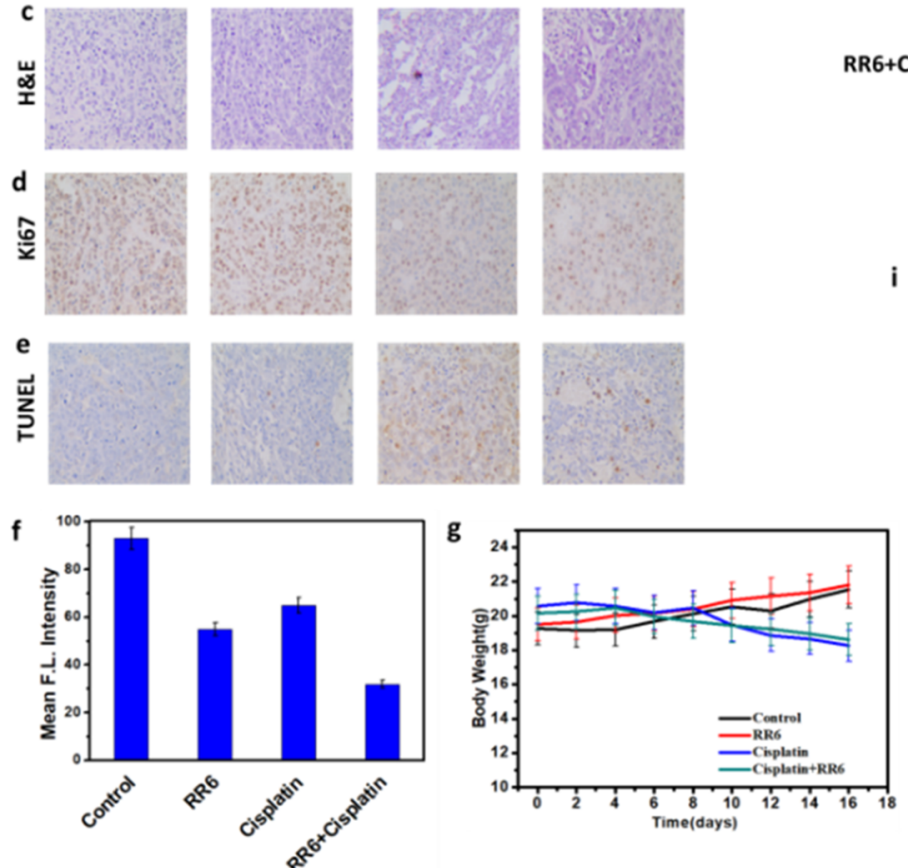

h

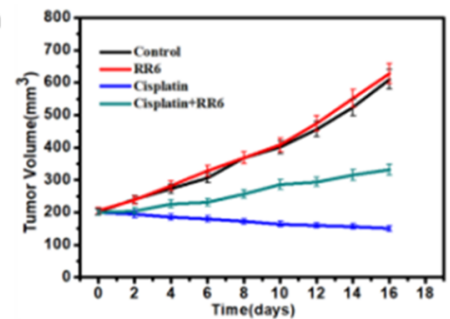

Figure 4. Effects of synergistic therapy of RR6 and cisplatin in the HepG2 tumor-bearing mice. (a) In vivo imaging for 30 min after being intratumorally injected with $\mathrm{Cy}-\mathrm{Pa}(100 \mu \mathrm{M}, 50 \mu \mathrm{L}$ in 1:99 DMSO/saline, v/v). (b) Ex vivo fluorescence imaging of the dissected heart, liver, spleen, lung, kidney, and tumor tissue in four groups in (a). (c) Representative slides of H\&E-stained tumors from sacrificed mice in (a). Magnification: $\times 400$. (d) Ki67 staining images of tumor tissues indicating cell proliferation. Magnification: $\times 400$. (e) TUNEL staining images of tumor tissues indicating cell apoptosis. Magnification: $\times 400$. (f) Mean fluorescence intensity of the images in (a). (g) Body-weight changes. (h) Tumor volume changes. (i) Representative photos of tumor tissue in every group.

tumors were established in nude mice, and tumor-bearing mice were divided into four groups. The first group was intraperitoneally injected with the same amount of normal saline. The second group was given $30 \mathrm{mg} / \mathrm{kg}$ RR6 orally once daily for 16 days. The third group received an intraperitoneal injection of cisplatin $(0.5 \mathrm{mg} / \mathrm{mL} \times 0.5 \mathrm{~mL})$ every other day for 16 days. The fourth group was given RR6 and cisplatin for 16 days with procedures similar to those described for the second and third groups. On the last day of treatment, we first measured the level of Vanin-1 with Cy-Pa. Forty minutes after the intratumoral injection of $\mathrm{Cy}-\mathrm{Pa}$, Vanin-1 was detected in tumor-bearing mice by an in vivo imaging system. Under different treatment conditions, the fluorescence intensity was as follows: control group > cisplatin group > RR6 group > RR6 + cisplatin group (Figures 4a and 5a). The changes in Vanin-1 levels in tumors were as expected, revealing the effective inhibition of Vanin-1 by RR6 in mice. The mean fluorescence intensity of Figures $4 \mathrm{a}$ and $5 \mathrm{a}$ was quantified in Figures $4 \mathrm{f}$ and $5 f$, respectively.

Subsequently, we evaluated the therapeutic efficacy of the combined application of RR6 and cisplatin on tumors in tumor-bearing mice during chemotherapy. First, the tumor sizes and body weights were recorded every other day over a 16-day period (Figures 4g,h and 5g,h). H\&E staining (Figures
$4 c$ and 5c), Ki67 immunohistochemistry (Figures 4d and 5d), and TUNEL staining (Figures $4 \mathrm{e}$ and $5 \mathrm{e}$ ) were used to examine the changes in pathological morphology. H\&E sections were used to assess the tumor tissue. As a kind of cell proliferation antigen, Ki67 reflects the activity of cell proliferation. Both the control group and the RR6 group maintained a high level of cell proliferation, and the cisplatin group showed a good inhibitory effect, but the addition of RR6 during chemotherapy offsets part of the inhibitory effect of cisplatin. Similar results were found in cisplatin-resistant tumor-bearing mice. TUNEL staining directly shows cleavage of DNA, and the TUNEL-positive rate represents the degree of cell damage, which can be used to evaluate cell apoptosis. During chemotherapy treatment of cancer, HepG2 and HepG2/DDP tumor cells showed satisfactory results, but the apoptosis rate in the combination group was lower than that in the chemotherapy group. Representative photos of tumor tissue in every group are shown (Figures $4 i$ and 5i). According to our experimental results, the addition of RR6 led to a decrease in the level of Vanin-1, which showed a protective effect on tumor cells during chemotherapy and reduced the therapeutic effect of chemotherapeutic drugs. This finding suggests that the active level of Vanin-1 may affect the cure rate of tumors and may also play an important role in the process of 

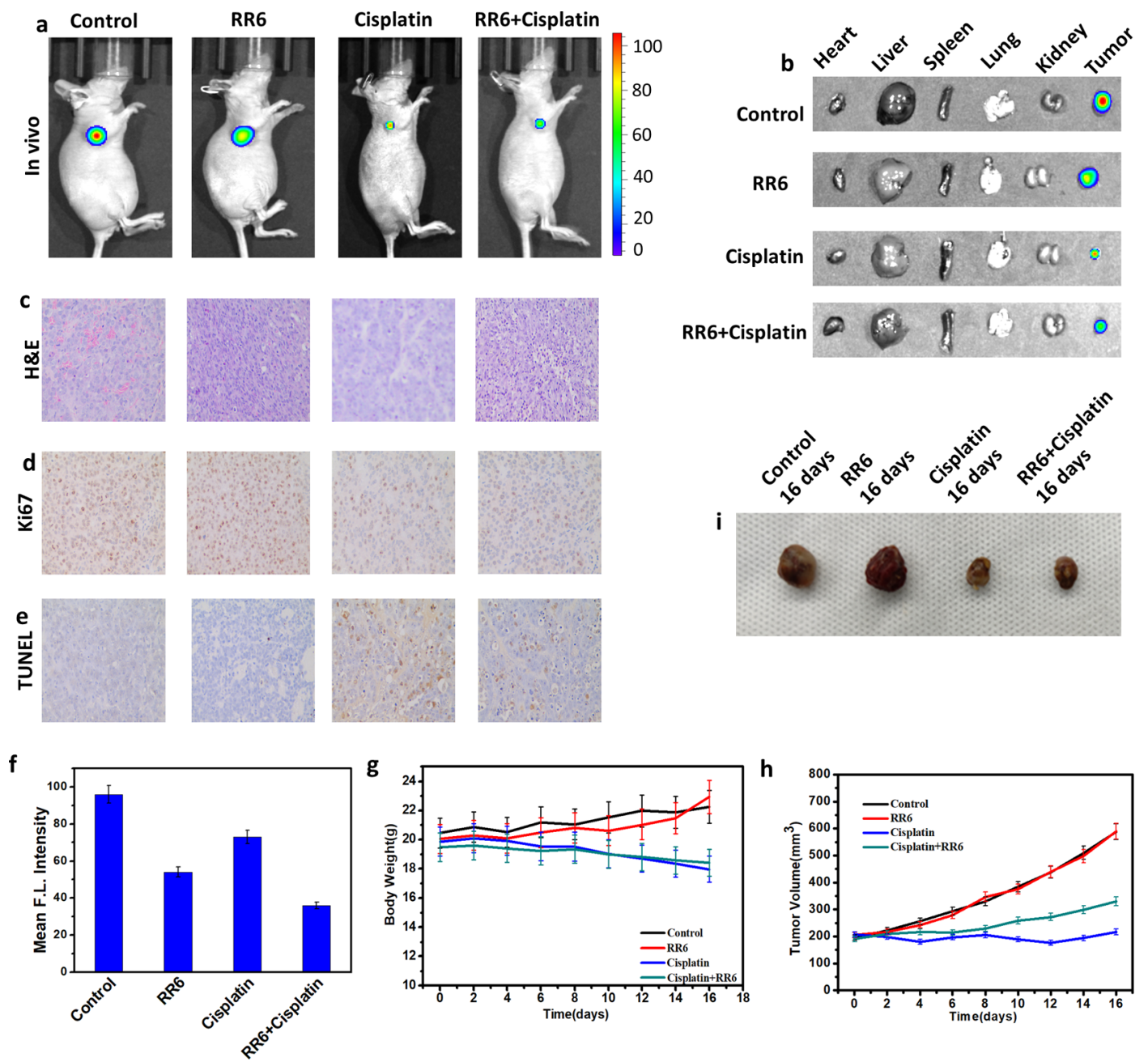

Figure 5. Effects of synergistic therapy with RR6 and cisplatin in the HepG2/DDP tumor-bearing mice. (a) In vivo imaging for 30 min after being intratumorally injected with Cy-Pa $(100 \mu \mathrm{M}, 50 \mu \mathrm{L}$ in 1:99 DMSO/saline, v/v). (b) Ex vivo fluorescence imaging of the dissected heart, liver, spleen, lung, kidney, and tumor tissue from the four groups in (a). (c) Representative slides of H\&E-stained tumors from sacrificed of mice in (a). Magnification: $\times 400$. (d) Ki67 staining images of tumor tissues indicating cell proliferation. Magnification: $\times 400$. (e) TUNEL staining images of tumor tissues indicating cell apoptosis. Magnification: $\times 400$. (f) Mean fluorescence intensity of the images (a). (g) Body-weight changes. (h) Tumor volume changes. (i) Representative photos of tumor tissue in every group.

drug resistance of tumors. These results provide some ideas for the treatment of cancer in the future.

\section{CONCLUSIONS}

In this study, we developed the NIR fluorescent probe Cy-Pa to detect changes in Vanin-1 levels in HepG2 cells and HepG2/DDP cells and in tumor-bearing mice. We also evaluated the anti-apoptotic effects of inhibiting Vanin-1 activity in living cells and in vivo. Our experiment proved that inhibition of Vanin-1 activity during tumor chemotherapy reduced the efficacy of the chemotherapeutic drug cisplatin, leading to a decrease in its therapeutic effectiveness in the tumor. This protective effect on cells may be attributed to the increase in GSH storage when the activity of Vanin-1 is inhibited, thus weakening the killing effect of chemotherapy on tumor cells. This phenomenon may be one of the reasons why chemotherapy is ineffective and drug resistance develops. Therefore, we should consider the activity of Vanin-1 during the tumor treatment process. The Cy-Pa probe developed in this study can accurately detect the activity changes of Vanin-1 in real-time at the cellular level and in vivo, which will contribute to the treatment of tumors.

\section{ASSOCIATED CONTENT}

\section{(s) Supporting Information}

The Supporting Information is available free of charge at https://pubs.acs.org/doi/10.1021/acs.analchem.1c02386.

General experimental section; synthetic procedures and characterization details of $\mathrm{Cy}-\mathrm{Pa}$; cytotoxicity of $\mathrm{Cy}-\mathrm{Pa}$; effects of $\mathrm{pH}$ on the probe $\mathrm{Cy}-\mathrm{Pa}$, the effect of RR6 and cisplatin on $\mathrm{Cy}-\mathrm{Pa}$; bright-field Images of Figure 2, bright-field images of Figure 3; characterization (MS, ${ }^{1} \mathrm{H}$ $\mathrm{NMR}$ and $\left.{ }^{13} \mathrm{C} \mathrm{NMR}\right)$ of synthesized $\mathrm{Pa}$ and $\mathrm{Cy}-\mathrm{Pa}$; and characterization (MS, ${ }^{1} \mathrm{H} \mathrm{NMR}$, and ${ }^{13} \mathrm{C} \mathrm{NMR}$ ) of synthesized $\mathrm{Pa}$ and Compound 1 (PDF)

\section{AUTHOR INFORMATION}

\section{Corresponding Authors}

Yan Huang - School of Pharmacy, Binzhou Medical

University, Yantai 264003, China; CAS Key Laboratory of Coastal Environmental Processes and Ecological Remediation, 
Yantai Institute of Coastal Zone Research, Chinese Academy of Sciences, Yantai 264003, China; Phone: +86-5352109130; Email: yhuang@yic.ac.cn

Xiaoyan Wang - School of Pharmacy, Binzhou Medical University, Yantai 264003, China; CAS Key Laboratory of Coastal Environmental Processes and Ecological Remediation, Yantai Institute of Coastal Zone Research, Chinese Academy of Sciences, Yantai 264003, China; Email: wangxy@ yic.ac.cn

Lingxin Chen - School of Pharmacy, Binzhou Medical University, Yantai 264003, China; CAS Key Laboratory of Coastal Environmental Processes and Ecological Remediation, Yantai Institute of Coastal Zone Research, Chinese Academy of Sciences, Yantai 264003, China; College of Chemistry and Chemical Engineering, Qufu Normal University, University, Qufu 273165, China; ○ orcid.org/0000-0002-3764-3515; Email: 1xchen@yic.ac.cn

\section{Authors}

Pengpeng Lu - School of Pharmacy, Binzhou Medical University, Yantai 264003, China; CAS Key Laboratory of Coastal Environmental Processes and Ecological Remediation, Yantai Institute of Coastal Zone Research, Chinese Academy of Sciences, Yantai 264003, China

Caiyun Zhang - School of Pharmacy, Binzhou Medical University, Yantai 264003, China

Lili Fu - School of Pharmacy, Binzhou Medical University, Yantai 264003, China; CAS Key Laboratory of Coastal Environmental Processes and Ecological Remediation, Yantai Institute of Coastal Zone Research, Chinese Academy of Sciences, Yantai 264003, China

Yinghui Wei - CAS Key Laboratory of Coastal Environmental Processes and Ecological Remediation, Yantai Institute of Coastal Zone Research, Chinese Academy of Sciences, Yantai 264003, China; Department of Respiratory Medicine, Binzhou Medical University Hospital, Binzhou 256603, China

Changjun Lv - Department of Respiratory Medicine, Binzhou Medical University Hospital, Binzhou 256603, China

Complete contact information is available at: https://pubs.acs.org/10.1021/acs.analchem.1c02386

\section{Notes}

The authors declare no competing financial interest.

\section{ACKNOWLEDGMENTS}

We thank the National Nature Science Foundation of China (Nos. 81573393, 21804010, 21976209, and 22007005), the Science and Technology Innovation Development Plan of Yantai of China (Nos. 2020MSGY113 and 2020YT06000898), the Research Initiation Fund of Binzhou Medical University (Grant Nos. BY2019KYQD39 and BY2020KYQD01), the Taishan Scholar Project Special Funding (No. ts20190962), the Shandong Peninsula Engineering Research Center of Comprehensive Brine Utilization (2018LS014)

\section{REFERENCES}

(1) Aurrand-Lions, M.; Galland, F.; Bazin, H.; Zakharyev, V. M.; Imhof, B. A.; Naquet, P. Immunity 1996, 5, 391-405.

(2) Pitari, G.; Malergue, F.; Martin, F.; Philippe, J. M.; Massucci, M. T.; Chabret, C.; Maras, B.; Dupre, S.; Naquet, P.; Galland, F. FEBS Lett. 2000, 483, 149-154.
(3) Maras, B.; Barra, D.; Dupre, S.; Pitari, G. FEBS Lett. 1999, 461, 149-152.

(4) Qian, J.; Teng, Z.; Wang, J.; Zhang, L.; Cao, T.; Zheng, L.; Cao, Y.; Qin, W.; Liu, Y.; Guo, H. ACS Sens. 2020, 5, 2806-2813.

(5) Yamashita, N.; Yashiro, M.; Ogawa, H.; Namba, H.; Nosaka, N.; Fujii, Y.; Morishima, T.; Tsukahara, H.; Yamada, M. Biochem. Biophys. Res. Commun. 2017, 489, 466-471.

(6) Di Leandro, L.; Maras, B.; Schinina, M. E.; Dupre, S.; Koutris, I.; Martin, F. M.; Naquet, P.; Galland, F.; Pitari, G. Free Radical Biol. Med. 2008, 44, 1088-1096.

(7) Boersma, Y. L.; Newman, J.; Adams, T. E.; Cowieson, N.; Krippner, G.; Bozaoglu, K.; Peat, T. S. Acta Crystallogr., Sect. D: Biol. Crystallogr. 2014, 70, 3320-3329.

(8) Chen, S.; Zhang, W.; Tang, C.; Tang, X.; Liu, L.; Liu, C. Diabetes 2014, 63, 2073-2085.

(9) van Diepen, J. A.; Jansen, P. A.; Ballak, D. B.; Hijmans, A.; Rutjes, F. P.; Tack, C. J.; Netea, M. G.; Schalkwijk, J.; Stienstra, R. Sci. Rep. 2016, 6, No. 21906.

(10) Fugmann, T.; Borgia, B.; Revesz, C.; Godo, M.; Forsblom, C.; Hamar, P.; Holthofer, H.; Neri, D.; Roesli, C. Kidney Int. 2011, 80, 272-281.

(11) Hosohata, K.; Washino, S.; Kubo, T.; Natsui, S.; Fujisaki, A.; Kurokawa, S.; Ando, H.; Fujimura, A.; Morita, T. Toxicology 2016, 359-360, 71-75.

(12) Hosohata, K.; Ando, H.; Fujimura, A. J. Pharmacol. Exp. Ther. 2012, 341, 656-662.

(13) Giessner, C.; Millet, V.; Mostert, K. J.; Gensollen, T.; Vu, M. T.; Garibal, M.; Dieme, B.; Attaf-Bouabdallah, N.; Chasson, L.; Brouilly, N.; Laprie, C.; Lesluyes, T.; Blay, J. Y.; Shintu, L.; Martin, J. C.; Strauss, E.; Galland, F.; Naquet, P. Life Sci. Alliance 2018, 1, No. e201800073.

(14) Daugherty, M.; Polanuyer, B.; Farrell, M.; Scholle, M.; Lykidis, A.; de Crecy-Lagard, V.; Osterman, A. J. Biol. Chem. 2002, 277, 21431-21439.

(15) Bartucci, R.; Salvati, A.; Olinga, P.; Boersma, Y. L. Int. J. Mol. Sci. 2019, 20, No. 3891.

(16) Hayes, J. D.; McLellan, L. I. Free Radical Res. 1999, 31, 273300.

(17) Dalton, T. P.; Shertzer, H. G.; Puga, A. Annu Rev Pharmacol Toxicol 1999, 39, 67-101.

(18) Wu, G.; Fang, Y. Z.; Yang, S.; Lupton, J. R.; Turner, N. D. J. Nutr. 2004, 134, 489-492.

(19) Sies, H. Free Radical Biol. Med. 1999, 27, 916-921.

(20) Circu, M. L.; Aw, T. Y. Free Radical Biol. Med. 2010, 48, 749762.

(21) Calvert, P.; Yao, K. S.; Hamilton, T. C.; O’Dwyer, P. J. Chem. Biol. Interact. 1998, 111-112, 213-224.

(22) Estrela, J. M.; Ortega, A.; Obrador, E. Crit. Rev. Clin. Lab. Sci. 2006, 43, 143-181.

(23) Zamble, D. B.; Lippard, S. J. Trends Biochem. Sci. 1995, 20, 435-439.

(24) Dasari, S.; Tchounwou, P. B. Eur. J. Pharmacol. 2014, 740, 364-378.

(25) Saad, S. Y.; Najjar, T. A.; Alashari, M. Clin. Exp. Pharmacol. Physiol. 2004, 31, 862-867.

(26) Kedar, U.; Phutane, P.; Shidhaye, S.; Kadam, V. Nanomed.: Nanotechnol., Biol., Med. 2010, 6, 714-729.

(27) Holohan, C.; Van Schaeybroeck, S.; Longley, D. B.; Johnston, P. G. Nat. Rev. Cancer 2013, 13, 714-726.

(28) Zahreddine, H.; Borden, K. L. Front. Pharmacol. 2013, 4, No. 28.

(29) Housman, G.; Byler, S.; Heerboth, S.; Lapinska, K.; Longacre, M.; Snyder, N.; Sarkar, S. Cancers 2014, 6, 1769-1792.

(30) Goto, S.; Yoshida, K.; Morikawa, T.; Urata, Y.; Suzuki, K.; Kondo, T. Cancer Res. 1995, 55, 4297-4301.

(31) Siddik, Z. H. Oncogene 2003, 22, 7265-7279.

(32) Friedman, M.; Noma, A. T.; Wagner, J. R. Anal. Biochem. 1979, 98, 293-304. 
(33) Hsiung, M.; Yeo, Y. Y.; Itiaba, K.; Crawhall, J. C. Biochem. Med.

1978, 19, 305-317.

(34) Newton, G. L.; Dorian, R.; Fahey, R. C. Anal. Biochem. 1981, 114, 383-387.

(35) Imai, K.; Toyo'Oka, T.; Watanabe, Y. Anal. Biochem. 1983, 128, 471-473.

(36) Jonas, A. J.; Schneider, J. A. Anal. Biochem. 1981, 114, 429432.

(37) Wittwer, C.; Wyse, B.; Hansen, R. G. Anal. Biochem. 1982, 122, 213-222.

(38) Duprè, S.; Chiaraluce, R.; Nardini, M.; Cannella, C.; Ricci, G.; Cavallini, D. Anal. Biochem. 1984, 142, 175-181.

(39) Ruan, B. H.; Cole, D. C.; Wu, P.; Quazi, A.; Page, K.; Wright, J. F.; Huang, N.; Stock, J. R.; Nocka, K.; Aulabaugh, A.; Krykbaev, R.; Fitz, L. J.; Wolfman, N. M.; Fleming, M. L. Anal. Biochem. 2010, 399, 284-292.

(40) Lin, Y.; Gao, Y.; Ma, Z.; Li, Z.; Tang, C.; Qin, X.; Zhang, Z.; Wang, G.; Du, L.; Li, M. Anal. Chem. 2018, 90, 9545-9550.

(41) Hu, Y.; Li, H.; Shi, W.; Ma, H. Anal Chem. 2017, 89, 1110711112.

(42) Ueno, T.; Urano, Y.; Setsukinai, K.; Takakusa, H.; Kojima, H.; Kikuchi, K.; Ohkubo, K.; Fukuzumi, S.; Nagano, T. J. Am. Chem. Soc. 2004, 126, 14079-14085.

(43) Ueno, T.; Urano, Y.; Kojima, H.; Nagano, T. J. Am. Chem. Soc. 2006, 128, 10640-10641.

(44) Jansen, P. A.; van Diepen, J. A.; Ritzen, B.; Zeeuwen, P. L.; Cacciatore, I.; Cornacchia, C.; van Vlijmen-Willems, I. M.; de Heuvel, E.; Botman, P. N.; Blaauw, R. H.; Hermkens, P. H.; Rutjes, F. P.; Schalkwijk, J. ACS Chem. Biol. 2013, 8, 530-534.

(45) Bernstein, C. N.; Blanchard, J. F.; Kliewer, E.; Wajda, A. Cancer 2001, 91, 854-862.

(46) Rachmilewitz, D.; Stamler, J. S.; Bachwich, D.; Karmeli, F.; Ackerman, Z.; Podolsky, D. K. Gut 1995, 36, 718-723.

(47) Belikova, N. A.; Vladimirov, Y. A.; Osipov, A. N.; Kapralov, A. A.; Tyurin, V. A.; Potapovich, M. V.; Basova, L. V.; Peterson, J.; Kurnikov, I. V.; Kagan, V. E. Biochemistry 2006, 45, 4998-5009.

(48) Porter, A. G.; Janicke, R. U. Cell Death Differ. 1999, 6, 99-104.

(49) Boulares, A. H.; Yakovlev, A. G.; Ivanova, V.; Stoica, B. A.; Wang, G.; Iyer, S.; Smulson, M. J. Biol. Chem. 1999, 274, 2293222940. 